\title{
Update of a comparative analysis of cost minimization following the introduction of newly available intravenous iron therapies in hospital practice
}

\author{
This article was published in the following Dove Press journal: \\ Therapeutics and Clinical Risk Management \\ 9 December 2011 \\ Number of times this article has been viewed
}

\section{Sunil Bhandari \\ Department of Renal Medicine, Hull and East Yorkshire Hospitals National Health Service Trust and Hull York Medical School, Kingston upon Hull, UK}

Correspondence: Sunil Bhandari Department of Renal Medicine, Hull and East Yorkshire Hospitals National Health Service Trust and Hull York Medical School, Kingston upon Hull, HU3 2JZ, UK

Tel +44 | 482674566

Fax +44 I48 2674998

Email sunil.bhandari@hey.nhs.uk
Background: The clinical need to be able to administer high doses of intravenous iron conveniently as a rapid infusion has been addressed by the recent introduction of ferric carboxymaltose and subsequently iron isomaltoside 1000. Neither requires a test dose. The maximum dose of ferric carboxymaltose is $1000 \mathrm{mg}$. The maximum dose of iron isomaltoside 1000 is based on $20 \mathrm{mg} / \mathrm{kg}$ body weight without a specified ceiling dose, thereby increasing the scope of being able to achieve total iron repletion with a single infusion. This ability to give high doses of iron is important in the context of managing iron deficiency anemia, which is associated with a number of clinical conditions where demands for iron are high. It is also an important component of the strategy as an alternative to blood transfusion. Affordability is a key issue for health services. Recent price changes affecting iron sucrose and ferric carboxymaltose, plus modifications to the manufacturers' prescribing information, have provoked this update.

Methods: This study is a comparative analysis of the costs of acquiring and administering the newly available intravenous iron formulations against standard treatments in the hospital setting. The costs include the medication, nursing costs, equipment, and patient transportation. Three dosage levels (600 mg, $1000 \mathrm{mg}$, and $1600 \mathrm{mg}$ ) are considered.

Results and conclusion: The traditional standard treatments, blood and iron sucrose, cost more than the alternative intravenous iron preparations across the dose spectrum and sensitivities. Low molecular weight iron dextran is the least expensive option at the $1600 \mathrm{mg}$ dose level but has the caveat of a prolonged administration time and requirement for a test dose. At $600 \mathrm{mg}$ and $1000 \mathrm{mg}$ dose levels, both iron isomaltoside 1000 and ferric carboxymaltose are more economical than low molecular weight iron dextran. Iron isomaltoside 1000 is less expensive than ferric carboxymaltose at all dose levels. Newly available iron preparations appear to be clinically promising, cost effective, and practical alternatives to current standards of iron repletion.

Keywords: iron isomaltoside 1000, ferric carboxymaltose, iron deficiency anemia, single high dose, IV iron, cost minimization

\section{Introduction}

The ability to administer high doses of intravenous (IV) iron rapidly, without the need for a test dose, is an important development in the strategy for treating iron deficiency anemia (IDA). Ferric carboxymaltose was the first IV iron to be introduced to the UK that did not require a test dose. It can be given rapidly and administered at up to $20 \mathrm{mg}$ per $\mathrm{kg}$ body weight to a ceiling of $1000 \mathrm{mg}$ per infusion. ${ }^{1}$ Iron isomaltoside 1000, whilst also administered rapidly, can be administered at up to $20 \mathrm{mg}$ of iron per 
$\mathrm{kg}$ of body weight. ${ }^{2}$ The absence of a specific dose ceiling for iron isomaltoside 1000 offers the opportunity to deliver very high doses (total doses) in a single administration. ${ }^{2}$ This may be of practical importance when calculating the treatment dose based on the Ganzoni formula that incorporates amounts for replenishing body iron stores. ${ }^{3}$ Doses for a number of disorders associated with IDA commonly require doses well in excess of $1000 \mathrm{mg} .{ }^{4-8}$

A prerequisite for undertaking a cost minimization study is establishing similarity of outcome from the treatment options. ${ }^{9}$ Iron treatment may be considered a "basic physiological requirement" (a micronutrient). ${ }^{10}$ There is no evidence to indicate that the choice of IV iron formulation affects the physiological uptake or iron metabolism. Thus, whilst the literature provides evidence of efficacy (as measured by a range of measurable outcomes) for each of the IV iron treatment options (including blood), there are no comparative data to suggest a physiological difference in performance. ${ }^{11-15}$ It is also recognized that the legacy of adverse events (ADEs) experienced with Imferon ${ }^{\circledR}$ (Fisons, Ipswich, UK), ${ }^{16}$ a high molecular weight iron dextran formulation withdrawn from the European market almost two decades ago, has been superseded by subsequent treatments which are associated with low levels of similar ADEs and, as such, any costs associated with ADEs are likely to be similar across the treatment options. ${ }^{1,2,16-19}$

The low level of ADEs associated with the two latest introductions (ferric carboxymaltose and iron isomaltoside 1000 ) is reflected in their approved modes of administration, as neither require the administration of a test dose. ${ }^{1,2}$ Patients receiving iron sucrose require a test dose prior to receiving their first dose. ${ }^{18}$ Those receiving low molecular weight iron dextran require a test dose at the time of each administration. ${ }^{19}$ The purpose of a test dose is to predose (challenge) with a small amount of iron (eg, 20-25 mg) of the chosen formulation followed by a period of observation to establish the likelihood of the formulation provoking an ADE. A test dose, followed by an observation period, extends the overall administration time and cost (nurse observation time). The arrival of two formulations where a test dose is explicitly excluded increases convenience (for both patients and health care professionals), reduces the overall administration time, and, furthermore, implicitly endorses the safety profile of the latest IV iron therapy options. ${ }^{1,2}$

The original paper examining the comparative costs of IV iron therapy and standard blood transfusions was first published in March 2011. ${ }^{20}$ However, a subsequent modification in the price of two of the products included in the initial analysis reduced the validity of the results. This subsequent study reflects the changed product acquisition costs, the current price of blood in England and Wales, and the most recently published nursing costs.

\section{Background}

Blood is a declining resource. The safety associated with the receipt of a blood infusion has progressively improved over the last decade but there are recognized risks (and costs) associated with a blood transfusion. ${ }^{21}$ Strategies to reduce the risks have led to the imposition of restrictions on members of the population who can be blood donors. This has resulted in a decline in the volume of blood donated. Additionally, following the identification of blood-borne diseases in blood donated by UK donors (eg, prion-related diseases, including Creutzfeldt-Jakob disease), certain cohorts of the population are prevented from receiving blood and blood products prepared from blood donated in the UK.

The National Blood Transfusion Service has encouraged the conservation and appropriate use of blood and blood products. ${ }^{15}$ The policy of reducing inappropriate blood use is aimed at reducing both the intrinsic risks associated with blood and risks associated with the process of matching and administration.

These developments have been at a time when the importance, implications, and prevalence of IDA is being appreciated and associated with a broad range of clinical conditions and situations, for example, in:

- chronic kidney disease patients, including renal transplant patients with/without erythropoietin replacement therapy

- patients undergoing various modes of dialysis therapy

- anemia associated with pregnancy (pre/postpartum, following hemorrhage)

- anemia following "high blood loss" surgical procedures; eliminating or reducing the need for postsurgery transfusion (eg, orthopedics, colorectal surgery)

- the elderly (often iron deficient and/or anemic); especially prior to surgery where blood loss may be significant

- IDA associated with anemia of chronic disease

- chronic IDA (often presenting with acute symptoms)

- chronic occult blood loss (inflammatory bowel disease)

- anemia associated with cancer or the use of chemotherapeutic agents

- menorrhagia (heavy uterine bleeding)

- chronic heart failure.

In these situations, iron-store repletion provides the substrate for erythropoiesis, thereby restoring or improving 
hemoglobin levels. This can commonly be achieved without the need for concomitant erythropoiesis-stimulating therapy. ${ }^{22}$

Anemia of chronic disease may be a comorbidity associated with a number of chronic conditions (eg, rheumatoid arthritis, inflammatory bowel disease). In these conditions, where hepcidin blocks both the absorption of iron from the gastrointestinal tract and mobilization of stored iron, IV iron has been demonstrated to bypass these blocks. ${ }^{23,24}$

Compared with oral iron, IV iron repletes iron stores more rapidly and can be given at high doses, as a total dose infusion, which improves compliance. ${ }^{2,19,25}$ Oral iron is associated with poor tolerance, poor compliance, and a high frequency of ADEs. ${ }^{26}$ It is poorly absorbed in patients with anemia of chronic disease and does not appear to bypass the immobilized iron stores. ${ }^{23,24}$ As such, its role as a useful source of iron supplementation is limited and its low cost often a "false economy." However, in spite of such caveats, it is still commonly used as first-line iron supplementation for patients diagnosed with chronic kidney disease.

The administration of IV iron may be considered a more physiological method of addressing chronic IDA than a blood transfusion. A transfusion addresses the acute symptoms of anemia, but is a poor and expensive source of iron, whereas IV iron provides physiologically available iron for both erythropoiesis and replenishing iron stores.

The purpose of this paper is to examine the comparative cost to the health care economy of the IV iron supplementation options, including blood transfusion. The economic importance is driven by the need to optimize the use of services in the current challenging financial climate whilst serving the needs of patients and maintaining patient safety. In these circumstances, value for money and the overall relative cost of treatments are important when making policy prescribing decisions. Given that all options will achieve similar clinical responses, a cost minimization analysis was undertaken to determine the least expensive option overall.

\section{Methods}

The costs of administering iron isomaltoside 1000 and ferric carboxymaltose are compared with the cost of administering a blood transfusion, iron sucrose, and low molecular weight iron dextran across a range of doses in a secondary care (hospital) setting. The cost model includes transportation, nursing, and equipment costs.

Initially, three matrix spreadsheets were established (one at each dose level) for the total costs of administering each of the options incorporating the sensitivity parameters (transport $10 \%$ and $20 \%$ of patients) and nurse grade ${ }^{6}$ (nurse team leader) and 7 (nurse team manager) (ie, four total costs for each treatment option at the three dose levels).

From these, for each treatment option, and at each dose level, a mean cost was established with the maximum and minimum levels taken from their respective sensitivity calculations (Table 4). This allowed a comparison to be made and provided an indication of the level of robustness of the relative costs.

Cost differences between each of the three traditional treatments were calculated with reference to each of the two recently introduced formulations using the mean costs with the differences calculated as an absolute and percentage difference (Table 5).

Finally, a direct "head to head" comparison at each dose level was undertaken between the mean cost of ferric carboxymaltose and iron isomaltoside 1000 that provides the actual and percentage differences for each dose level (Table 6).

\section{Parameters for the revised cost model}

\section{Standard treatment comparators}

Standard treatment will vary according to local practice and medical specialty. Traditionally, blood would have been the sole option in most of the indications/situations described. IV iron is used almost exclusively in

Table I Comparative intravenous drip infusion regimens ${ }^{1,2,18,19,27}$

\begin{tabular}{|c|c|c|c|c|c|}
\hline Product & Iron sucrose & $\begin{array}{l}\text { Low molecular } \\
\text { weight iron dextran }\end{array}$ & $\begin{array}{l}\text { Iron isomaltoside } \\
1000\end{array}$ & Ferric carboxymaltose & Blood \\
\hline Dose limitation & $100 \mathrm{mg}$ or $200 \mathrm{mg}$ & $100-200 \mathrm{mg}$ & $\begin{array}{l}20 \mathrm{mg} / \mathrm{kg} \text { body weight to total } \\
\text { body weight }\end{array}$ & $\begin{array}{l}20 \mathrm{mg} / \mathrm{kg} \text { up to } \max \\
1000 \mathrm{mg}\end{array}$ & None \\
\hline $\begin{array}{l}\text { Rate of } \\
\text { administration }\end{array}$ & $\begin{array}{l}100 \mathrm{mg} \text { in } 15 \mathrm{mins} \\
200 \mathrm{mg} \text { in } 30 \mathrm{mins}\end{array}$ & $\begin{array}{l}100 \mathrm{mg} \text { in } 37.5 \mathrm{mins} \\
200 \mathrm{mg} \text { in } 41.25 \mathrm{mins}\end{array}$ & $\begin{array}{l}0-5 \mathrm{mg} / \mathrm{kg} \text { body weight in } 15 \mathrm{mins} \\
6-10 \mathrm{mg} / \mathrm{kg} \text { body weight in } 30 \mathrm{mins} \\
\mathrm{I}-20 \mathrm{mg} / \mathrm{kg} \text { body weight in } 60 \mathrm{mins}\end{array}$ & $\begin{array}{l}100 \mathrm{mg} \text { to } 200 \mathrm{mg} \text { no } \\
\text { minimum time quoted } \\
\geq 200-500 \mathrm{mg} 6 \text { mins } \\
\geq 500-1000 \mathrm{mg} 15 \mathrm{mins}\end{array}$ & $\begin{array}{l}\text { I unit } \\
\text { (equ } 200 \mathrm{mg} \\
\text { iron) } 90 \mathrm{mins}\end{array}$ \\
\hline Test dose & $\begin{array}{l}\text { Required for first } \\
\text { administration }\end{array}$ & $\begin{array}{l}\text { Required at each } \\
\text { administration }\end{array}$ & Not required & Not required & N/A \\
\hline
\end{tabular}

Abbreviations: equ, equivalent; N/A, not applicable. 
Table 2 Comparative intravenous injection regimens $s^{1,2,18,19}$

\begin{tabular}{|c|c|c|c|c|c|}
\hline Product & Iron sucrose & $\begin{array}{l}\text { Low molecular weight } \\
\text { iron dextran }\end{array}$ & $\begin{array}{l}\text { Iron isomaltoside } \\
1000\end{array}$ & Ferric carboxymaltose & Blood \\
\hline Dose limitation & $200 \mathrm{mg}$ & $200 \mathrm{mg}$ & $200 \mathrm{mg}$ & $1000 \mathrm{mg}$ & N/A \\
\hline $\begin{array}{l}\text { Rate of } \\
\text { administration }\end{array}$ & $\begin{array}{l}100 \mathrm{mg} \text { in } 5 \text { mins } \\
\text { minimum }-10 \text { mins maximum } \\
200 \mathrm{mg} \text { in } 10 \text { mins } \\
\text { minimum }-20 \text { mins maximum }\end{array}$ & $\begin{array}{l}100 \mathrm{mg} \text { in } 25 \mathrm{mins} \\
200 \mathrm{mg} \text { in } 35 \mathrm{mins}\end{array}$ & $2-4$ mins & $\begin{array}{l}>200-500 \mathrm{mg} \text { at } 100 \mathrm{mg} / \mathrm{min} \\
500-1000 \mathrm{mg} \text { over } 15 \mathrm{mins}\end{array}$ & N/A \\
\hline Test dose & $\begin{array}{l}\text { Required for first } \\
\text { administration }\end{array}$ & $\begin{array}{l}\text { Required at each } \\
\text { administration }\end{array}$ & Not required & Not required & N/A \\
\hline
\end{tabular}

Abbreviation: N/A, not applicable.

hemodialysis patients, whereas, in other situations, IV iron is progressively replacing the practice of administering a blood transfusion.

As a standard treatment, blood is included as a comparator. Iron sucrose (considered a standard treatment) and low molecular weight iron dextran are also used as comparators.

\section{Dose levels}

The comparator doses were chosen to reflect clinical practice. Blood is transfused in multiples of "units." Each unit may be considered to approximate $200 \mathrm{mg}$ of elemental iron.

Iron doses are commonly calculated using the Ganzoni formula. ${ }^{3}$ It is not uncommon for an individual's requirement to be up to $2000 \mathrm{mg}$ or higher across the range of conditions associated with anemia. ${ }^{4-8}$

For the purposes of this cost minimization modeling, three levels of administration were chosen (to provide a dose sensitivity matrix): $600 \mathrm{mg}, 1000 \mathrm{mg}$, and $1600 \mathrm{mg}$. These allowed direct comparison with units of blood.

\section{Bioavailability and efficacy}

In preparing this cost minimization model, it was assumed that each of the IV iron preparations impact erythropoiesis and enter iron stores in a similar manner directly related to the dose administered. There is no evidence to suggest that incorporation of iron into reticulocytes, elevation of hemoglobin levels, and development of iron stores differs. ${ }^{28-32}$
The administration of IV iron differs physiologically to the administration of a blood transfusion. Blood results in an immediate rise in hemoglobin level. Iron from a blood transfusion is then recycled as the erythrocytes expire, but the resulting elevation in iron stores and hemoglobin level are considered to be similar for the purposes of this study.

\section{ADEs}

In the cost modeling, no allowance was made for occurrence of ADEs. These are infrequent and similar for iron sucrose and low molecular weight iron dextran. ${ }^{17-19}$ The summaries of product characteristics for iron isomaltoside 1000 and ferric carboxymaltose indicate that ADEs associated with their use will be similar to those of currently available IV iron formulations. ${ }^{1,2,18,19}$

Blood has higher levels of risk, both as a product per se and from the potential human error associated with compatibility testing and administration. However, no cost has been allocated to the treatment of these ADEs.

\section{Dose and rate of administration limitations}

In the cost modeling, the dose (including any constraints), rate of administration, and need for a test dose were taken from the manufacturers' prescribing information (Tables 1-3).

The manufacturers' instructions for undertaking a test dose were carefully incorporated into the modeling. For example, in the case of low molecular weight iron dextran, when administered for the first time, a $25 \mathrm{mg}$ dose is given and the patient

Table 3 Comparative high dose infusion regimens $s^{1,2,18,19}$

\begin{tabular}{|c|c|c|c|c|c|}
\hline Product & Iron sucrose & $\begin{array}{l}\text { Low molecular weight } \\
\text { iron dextran }\end{array}$ & $\begin{array}{l}\text { Iron isomaltoside } \\
1000\end{array}$ & Ferric carboxymaltose & Blood \\
\hline Dose limitation & $200 \mathrm{mg}$ & $20 \mathrm{mg} / \mathrm{kg}$ & $20 \mathrm{mg} / \mathrm{kg}$ & 20 mg/kg max 1000 mg & N/A \\
\hline $\begin{array}{l}\text { Rate of } \\
\text { administration }\end{array}$ & N/A* & $\begin{array}{l}20 \mathrm{mg} / \mathrm{kg} \text { first } 25 \mathrm{mg} \text { (test dose) } \\
\text { over } 15 \text { mins then balance over } 4 \text { hours }\end{array}$ & $\begin{array}{l}0-10 \mathrm{mg} / \mathrm{kg} \text { in } 30 \mathrm{mins} \\
\mathrm{II}-20 \mathrm{mg} / \mathrm{kg} \text { in } 60 \mathrm{mins}\end{array}$ & $\begin{array}{l}\geq 200-500 \mathrm{mg} 6 \mathrm{mins} \\
\geq 500-1000 \mathrm{mg} 15 \mathrm{mins}\end{array}$ & $N / A$ \\
\hline Test dose & N/A & Required at each administration & Not required & Not required & N/A \\
\hline
\end{tabular}

Note: *Requires multiple administrations of $200 \mathrm{mg}$ intravenous injections to deliver total dose.

Abbreviation: N/A, not applicable. 
Table 4 Mean (with maximum and minimum range) comparative treatment costs for administering intravenous iron at three dose levels $(600 \mathrm{mg}, 1000 \mathrm{mg}$ and, $1600 \mathrm{mg})$

\begin{tabular}{|c|c|c|c|c|c|}
\hline & \multicolumn{5}{|c|}{ Comparative costs, GBPE } \\
\hline & Iron sucrose & $\begin{array}{l}\text { Low molecular weight } \\
\text { iron dextran }\end{array}$ & $\begin{array}{l}\text { Iron isomaltoside } \\
1000\end{array}$ & $\begin{array}{l}\text { Ferric } \\
\text { carboxymaltose }\end{array}$ & Blood \\
\hline \multicolumn{6}{|c|}{$600 \mathrm{mg}$ iron } \\
\hline Mean & 261.61 & 221.19 & $170.2 \mid$ & 173.23 & 449.80 \\
\hline Min & 241.61 & 206.88 & 163.54 & 164.94 & 442.67 \\
\hline Max & 281.61 & 235.49 & 176.87 & 181.52 & 456.92 \\
\hline \multicolumn{6}{|c|}{1000 mg iron } \\
\hline Mean & 436.02 & 253.07 & 231.71 & 249.63 & 737.55 \\
\hline Min & 402.68 & 238.76 & 225.50 & 241.34 & 727.67 \\
\hline Max & 469.35 & 267.37 & 237.92 & 257.92 & 747.42 \\
\hline \multicolumn{6}{|c|}{$1600 \mathrm{mg}$ iron } \\
\hline Mean & 697.63 & 300.89 & 333.41 & 404.86 & 1169.17 \\
\hline Min & 644.29 & 286.58 & 327.20 & 394.27 & 1155.17 \\
\hline Max & 750.96 & 315.19 & 339.62 & 415.44 & 1183.17 \\
\hline
\end{tabular}

observed for 45 minutes. ${ }^{19}$ The balance can then be administered if there are no ADEs. For the second and subsequent infusions, the first $25 \mathrm{mg}$ of iron is infused over 15 minutes and, if there are no untoward events, the administration can be continued. ${ }^{19}$ When a total dose is administered, the patient should be observed for a further hour after the completion of the administration. ${ }^{19}$ For the administration of iron sucrose, a test dose is required only for the first administration to a patient. ${ }^{18}$

For the purposes of this study, it was assumed that this was the second (or subsequent) administration to a patient of iron sucrose and low molecular weight iron dextran. For the specified range of doses, an observation period was included in the administration times for low molecular weight iron dextran (as indicated in the manufacturer's prescribing information). ${ }^{19}$ Given the recommended dilution volume for preparing the infusion, it was assumed that the administration plus observation period would be similar at each dose level - that is, 6 hours in total. In this analysis, 10 minutes was allowed for setup time across the range of preparations.

\section{Transportation}

This is an important factor when considering IV iron supplementation. Across the spectrum of patients with IDA, a proportion will be short of breath, perhaps with palpitations; will invariably be nonambulatory; and will be transported to hospital on a stretcher or in a wheelchair. Additionally, a number will be elderly, frail, and disabled. In the UK, ambulance services are paid for by the National Health Service. Two types of "transported" patient are considered: (1) those who are ambulatory, where the charge is GBP£12.00/single journey (GBP£24.00 return) and (2) those who are in a wheelchair or who require a stretcher where the charge for a single journey is GBP£48.00 single (GBP£96.00 return). ${ }^{33}$

Across the spectrum of causes of IDA, it is difficult to establish the specific proportion of patients who require transportation and the ratio between ambulatory and nonambulatory patients. In this study, a sensitivity of $10 \%$ and $20 \%$ of patients requiring treatment is used. These percentages are to reflect transport requirements across the spectrum of patients with IDA.

Table 5 Relative cost position (mean) of iron isomaltoside 1000 and ferric carboxymaltose at three dose levels compared to standard treatments and blood

\begin{tabular}{|c|c|c|c|}
\hline & \multicolumn{3}{|l|}{ Cost difference, GBPE ( $\pm \%)$} \\
\hline & $\begin{array}{l}\text { Iron isomaltoside } 1000 \text { vs } \\
\text { iron sucrose }\end{array}$ & $\begin{array}{l}\text { Iron isomaltoside } 1000 \text { vs } \\
\text { low molecular weight iron dextran }\end{array}$ & $\begin{array}{l}\text { Iron isomaltoside } 1000 \text { vs } \\
\text { blood }\end{array}$ \\
\hline $600 \mathrm{mg}$ dose & $-91.40(-34.93 \%)$ & $-50.98(-23.05 \%)$ & $-279.59(-62.16 \%)$ \\
\hline $1000 \mathrm{mg}$ dose & $-204.3 \mathrm{I}(-46.86 \%)$ & $-21.36(-8.44 \%)$ & $-505.84(-68.58 \%)$ \\
\hline \multirow[t]{2}{*}{$1600 \mathrm{mg}$ dose } & $-364.22(-52.21 \%)$ & $+32.52(+\mid 0.81 \%)$ & $-835.76(-7 \mid .48 \%)$ \\
\hline & $\begin{array}{l}\text { Ferric carboxymaltose vs } \\
\text { Iron sucrose }\end{array}$ & $\begin{array}{l}\text { Ferric carboxymaltose vs } \\
\text { low molecular weight iron dextran }\end{array}$ & $\begin{array}{l}\text { Ferric carboxymaltose vs } \\
\text { blood }\end{array}$ \\
\hline $600 \mathrm{mg}$ dose & $-88.38(-33.78 \%)$ & $-47.96(-21.68 \%)$ & $-276.57(-61.49 \%)$ \\
\hline $1000 \mathrm{mg}$ dose & $-186.39(-42.75 \%)$ & $-3.44(-1.36 \%)$ & $-487.92(-66.15 \%)$ \\
\hline $1600 \mathrm{mg}$ dose & $-292.77(-41.97 \%)$ & +103.97 (+34.55\%) & $-764.31(-65.37 \%)$ \\
\hline
\end{tabular}


Table 6 Relative cost position (mean) of iron isomaltoside 1000 versus ferric carboxymaltose at three dose levels of iron (600 mg, $1000 \mathrm{mg}$ and, $1600 \mathrm{mg})$

\begin{tabular}{llll}
\hline & Mean cost iron isomaltoside & $\begin{array}{l}\text { Mean cost ferric carboxymaltose } \\
\text { (GBPE) }\end{array}$ & $\begin{array}{l}\text { Mean cost saving iron isomaltoside } \\
\text { I 000 vs ferric carboxymaltose (GBPE) }\end{array}$ \\
\hline $600 \mathrm{mg}$ dose & $1000($ GBPE) & 173.23 & $3.02(1.74 \%)$ \\
$1000 \mathrm{mg}$ dose & 231.71 & 249.63 & $17.92(7.18 \%)$ \\
$1600 \mathrm{mg}$ dose & 333.41 & 404.86 & $71.45(17.65 \%)$ \\
\hline
\end{tabular}

For example, few anemic pregnant women will require transport, but there will be a high demand for transportation by those undergoing dialysis or elderly persons undergoing surgery. It is assumed that those requiring transport will be equally split between those who are ambulatory and those who are nonambulatory (who require a stretcher or wheelchair).

\section{Giving sets, cannula, and dressing}

For the purpose of this analysis, unit costs reported by Bhandari and Naudeer ${ }^{34}$ were used. These were GBP£7.89 for a "giving set," GBP£0.74 for one cannula, and GBP£0.54 for a standard dressing.

\section{Nursing time}

The costs for 1 hour of patient-contact nursing time in the $\mathrm{UK}$ at midband 6 and 7 have risen to GBP£70.00 (+4.5\%) and GBP£81.00 (+5.2\%), respectively, and reflect the latest figures published by the Personal Social Services Research Unit (2009/10). ${ }^{35,36}$ Nurse grades 6 (nurse team leader) and 7 (nurse team manager) are used to reflect the level of knowledge, experience, and responsibility required to run a nurse-led "anemia" service.

In the cost allocations, assumptions are made with regard to allocating time to represent multitasking (ie, not dedicating sole time to an individual patient during a 6-hour low molecular weight iron dextran total dose infusion administration). Thus, for a short administration (approximately 30 minutes) time, a nurse is likely to attend for the duration. For an infusion taking about 60 minutes it is assumed that the nurse will spend $50 \%$ of their time with the patient, whereas, for a prolonged infusion of low molecular weight iron dextran, a nurse is considered to spend $33 \%$ of their time with the patient. (During the test-dose phase and observation phase this may be $100 \%$.) The differences in administration times are reflected in the nursing time and, therefore, nurse costs required for the administration of each treatment option at each dose level.

\section{Cost of IV iron products}

Recent price modifications are now used. For $200 \mathrm{mg}$ iron, these are GBP£18.70 (+10\%) for iron sucrose, ${ }^{37} \mathrm{GBP} £ 15.94$ for low molecular weight iron dextran, ${ }^{38}$ GBP£38.20 $(-12.2 \%)$ for ferric carboxymaltose, ${ }^{39}$ and GBP£33.90 for iron isomaltoside $1000 .^{40}$

\section{Cost of blood}

The cost used in this modeling is now updated to that charged in England and Wales to NHS hospitals for 2010/11, which is GBP£125.00/unit (-6.37\%) for red blood cells. (This does not include the cost of pretransfusion cross matching of a patient's blood or error checking. ${ }^{41}$ )

\section{Other costs}

Expenditure considered minor or unlikely to be significant to the outcomes was excluded. This can be justified on the basis that, in any particular unit, the practice is likely to have a similar impact across the IV iron options. A cost deliberately omitted was that of the clinician. Whilst likely to be available during a transfusion, they would be undertaking other clinical/administrative duties, whereas a nurse would normally be responsible for administering the infusion and managing/monitoring the procedure. An example of a minor cost not included is that of the infusion fluid (normal saline), which costs GBP£0.70 per $250 \mathrm{~mL}{ }^{34}$

\section{Results}

From Table 4, it is observed that both iron isomaltoside 1000 and ferric carboxymaltose are the lower cost options when compared with iron sucrose and blood at each dose level and across all levels of sensitivity. When compared with low molecular weight iron dextran, both have a lower cost at the $600 \mathrm{mg}$ and $1000 \mathrm{mg}$ level, however, at the $1600 \mathrm{mg}$ dose level, low molecular weight iron dextran offers a lower cost than both ferric carboxymaltose and iron isomaltoside 1000 .

This same table indicates that low molecular weight iron dextran is less expensive than iron sucrose across the dose spectrum and across the sensitivity ranges. Blood is the highest cost option and this is without including the costs of cross matching. 
The actual cost and percentage differences accruing from using either iron isomaltoside 1000 or ferric carboxymaltose compared with the current standard treatments are illustrated in Table 5. It is apparent throughout that greater savings are potentially realizable by adopting iron isomaltoside 1000 instead of ferric carboxymaltose and, on the single occasion that a traditional therapy is less expensive (ie, $1600 \mathrm{mg}$ dose of low molecular weight iron dextran), the saving is GBP£103.97 compared with ferric carboxymaltose but only GBP£32.52 when compared with iron isomaltoside 1000 .

A direct comparison of the cost of using the latest two entrants at the three dose levels is presented in Table 6. The potential expenditure savings from using iron isomaltoside 1000 at each dose level range from GBP£3.02 at the $600 \mathrm{mg}$ dose level (1.74\%), to GBP£71.45 at the $1600 \mathrm{mg}$ dose level (17.65\%).

\section{Discussion}

Blood continues to be used to treat IDA, in the absence of acute blood loss, associated with a number of conditions. This is against NHS Blood and Transplant policies to reduce blood use, which include the use of IV iron as an alternative to blood..$^{15}$ There is, however, momentum gaining pace toward treating IDA with iron supplementation (normally with IV iron).

Renal medicine has been at the forefront of pioneering the use of IV iron. This practice historically developed following the introduction of iron sucrose. Iron sucrose can be administered in doses of up to $200 \mathrm{mg}$ in a single administration and, as such, it was adopted in hemodialysis units. It is normally given to patients during one of their weekly hemodialysis sessions. This use of IV iron has resulted in a dramatic reduction in the requirement for blood transfusion.

The results of this updated cost minimization modeling (Tables 4 and 5) indicate that each of the IV iron options are less expensive than administering a blood transfusion at each iron repletion level and thereby may further encourage the consideration of iron as an alternative to blood in patients with IDA, especially in those diagnosed with chronic IDA.

Iron sucrose is well established as a standard treatment for IDA, however, its use is constrained by the maximum amount that can be given in a single administration. This is particularly pertinent when considering total iron repletion requirements. The Ganzoni formula is widely used to calculate these requirements. ${ }^{3}$ This formula embraces repletion of iron stores (frequently $500 \mathrm{mg}$ of iron). The resulting dose calculation, depending on the weight of the patient, prevailing hemoglobin level, target hemoglobin level, and cause of IDA, may be well above $1000 \mathrm{mg}$ and may exceed $2000 \mathrm{mg}$. To achieve repletion with iron sucrose would require multiple administrations of $200 \mathrm{mg}$ doses, which is impractical and inconvenient. Furthermore, apart from blood, it is the least attractive option from a cost perspective across the dose range under consideration.

Since the withdrawal of Imferon ${ }^{\circledR}$ (high molecular weight iron dextran), low molecular weight iron dextran, available in the UK since the 1990s, has been at the forefront for clinicians wishing to administer large doses of iron at a single clinic visit. However, the prolonged infusion time may be considered a disadvantage both for the health service provider and the patient.

In this analysis, low molecular weight iron dextran has been shown to be less expensive than the standard treatments of blood and iron sucrose across the dose range. When compared to the more recently introduced options (ferric carboxymaltose and iron isomaltoside 1000) it is more expensive at the $600 \mathrm{mg}$ and $1000 \mathrm{mg}$ dose levels. At the $1600 \mathrm{mg}$ dose level, ferric carboxymaltose is $34.6 \%$ more expensive to administer. Whilst iron isomaltoside 1000 is also more expensive, the difference is much less at 10.8\% (GBP£32.52) and may perhaps be preferred (and justified) given the much reduced time required for administration, patient convenience, and potential increase in patient throughput (especially in the "payment by results" environment).

The direct comparison between iron isomaltoside 1000 and ferric carboxymaltose (Table 6) suggests that iron isomaltoside 1000 offers potential savings when compared with ferric carboxymaltose at all three dose levels but especially at the higher dose end of the spectrum.

In the modeling, key "drivers" are cost of medication, time for administration (affecting nurse resource), and transportation. The cost of the various iron formulations are National Health Service acquisition costs. The choice of available IV treatment options is limited to those included in this analysis.

This analysis has not embraced oral iron supplementation. It is acknowledged that oral iron has a significant role in preventing and treating IDA and has a much lower cost than either IV iron formulations or blood. However, the patient population that receive IV iron or blood is largely defined as those for whom oral iron is not appropriate, where oral iron has not been tolerated, has resulted in an unacceptable level of side effects, where compliance is poor, or where treatment has not achieved target iron parameters (ie, hemoglobin or ferritin levels). ${ }^{1,2,18,19}$ There is evidence to indicate that IV iron will achieve target parameters more quickly than oral 
iron and, more importantly, when compared with oral iron, overcomes the "hepcidin block" affecting iron absorption and mobilization of iron stores in patients where IDA is associated with chronic conditions. ${ }^{23-25}$ The ability to give a total dose repletion rapidly, in a single infusion, overcomes compliance issues and is highly convenient for a number of patient types (eg, the elderly, in pregnancy). It may be justified on the basis of achieving target hemoglobin and ferritin levels more rapidly than oral iron - for example, prior to elective surgery - thereby reducing the incidence of cancellations due to poor anemic status.

\section{Conclusion}

Parenteral iron treatment has advanced significantly as a result of the introduction of ferric carboxymaltose and subsequently iron isomaltoside 1000. The scope for administering rapid single high doses of iron, without the need for a test dose, to address IDA associated with various clinical conditions, is a welcome development. This further enhances the prospect of using IV iron as an alternative to a blood transfusion for treating chronic IDA. This may be particularly important in the strategy of reducing blood use and reducing the incidence and volume of blood transfusions in the UK. It is particularly pertinent to note that this can be undertaken at a cost well below that of blood.

This updated analysis confirms that blood as a source of iron is expensive and is the least attractive option from a cost perspective. Iron sucrose, in addition to being able to be administered only in small $200 \mathrm{mg}$ doses and requiring a test dose, is more expensive than the other available IV iron alternatives. Only at the highest dose level (1600 mg) does low molecular weight iron dextran offer cost savings worthy of any consideration compared with the two newest entrants.

Ferric carboxymaltose has a lower cost than iron sucrose and blood across the dose range; is only noticeably more expensive than low molecular weight iron dextran at the $1600 \mathrm{mg}$ level, where the cost difference has to be balanced against administration time, convenience, and patient throughput. It is, however, more expensive than iron isomaltoside 1000 at each dose level (progressively, GBP£3.02 at $600 \mathrm{mg}$, GBP£17.92 at $1000 \mathrm{mg}$, and GBP£71.45 at the $1600 \mathrm{mg}$ dose levels).

Likewise, iron isomaltoside 1000 has a lower cost than iron sucrose and blood across the dose range; it compares favorably with low molecular weight iron dextran at the $600 \mathrm{mg}$ and $1000 \mathrm{mg}$ dose levels but is marginally more expensive at the $1600 \mathrm{mg}$ level. Cost savings compared to ferric carboxymaltose prevail across the dose range but are less pronounced than previously published following this product's price reduction.

This analysis of the relative holistic cost of administering the treatment options endeavors to more closely reflect the "real world" situation when making prescribing policy decisions associated with the treatment of IDA.

\section{Disclosure}

The author reports no conflicts of interest in this work.

\section{References}

1. Ferinject [summary of product characteristics]. London: Vifor Pharma UK Ltd; 2011 [updated October 25]. Available at: http://www.medicines. org.uk/EMC/medicine/24167/SPC/Ferinject+(ferric+carboxymaltose) 1. Accessed November 9, 2011.

2. Monofer $100 \mathrm{mg} / \mathrm{mL}$ solution for injection/infusion [summary of product characteristics]. London: Pharmacosmos UK Ltd; 2011 [updated March 21]. Available at: http://www.medicines.org.uk/EMC/ medicine/23669/SPC/Monofer+100 mg+ml+solution+for+injection+ infusion/. Accessed October 19, 2011.

3. Ganzoni AM. Intravenous iron-dextran: therapeutic and experimental possibilities. Schweiz Med Wochenschr. 1970;100:301-303. German.

4. Peebles G, Fenwick S. Intravenous iron administration in a short-stay hospital setting. Nurs Stand. 2008;22:35-41.

5. Gasche C, Berstad A, Befrits R, et al. Guidelines on the diagnosis and management of iron deficiency and anemia in inflammatory bowel diseases. Inflamm Bowel Dis. 2007;13:1545-1553.

6. Breymann C. The use of iron sucrose complex for anemia in pregnancy and the postpartum period. Semin Hematol. 2006;43(Suppl 6): S28-S31.

7. Bokemeyer C, Aopro MS, Courdi A, et al. EORTC guidelines for the use of erythropoietic proteins in anemic patients with cancer. Eur J Cancer. 2004;40:2201-2216.

8. Auerbach M, Ballard H, Trout JR, et al. Intravenous iron optimizes the response to recombinant human erythropoietin in cancer patients with chemotherapy-related anemia: a multicenter, open-label, randomized trial. J Clin Oncol. 2004;22:1301-1307.

9. Haycox A. What is cost-minimisation analysis? What is ...? Series. London: Hayward Medical Communications; 2009. Available at: http://www.medicine.ox.ac.uk/bandolier/painres/download/whatis/ What_is_cost-min.pdf. Accessed October 3, 2011.

10. Higdon J. Iron [web page on the Internet]. Corvallis, OR: Linus Pauling Institute. Available from: http://lpi.oregonstate.edu/infocenter/minerals/ iron/. Accessed October 3, 2011.

11. Moniem KA, Bhandari S. Tolerability and efficacy of parenteral iron therapy in hemodialysis patients, a comparison of preparations. Transfus Altern Transfus Med. 2007;9(1):37-42.

12. Moore RA, Gaskell H, Rose P, Allan J. Meta-analysis of efficacy and safety of intravenous ferric carboxymaltose (Ferinject) from clinical trial reports and published trial data. BMC Blood Disord. 2011;11:4.

13. Hildebrandt PR, Brunn NE, Nielsen OW, et al. Effects of administration of iron isomaltoside 1000 in patients with chronic heart failure. A pilot study. Transfus Altern Transfus Med. 2010;11(4):131-137.

14. Bjorn W, Bhandari S, Barany P, et al. Iron isomaltoside 1000: a new intravenous iron for treating iron deficiency in chronic kidney disease. J Nephrol. 2011;24(5):589-596.

15. Department of Health. Better Blood Transfusion: Safe and Appropriate Use of Blood. Health Service Circular HSC 2007/001. London: Department of Health; 2007. Available from: http://www.dh.gov.uk/ prod_consum_dh/groups/dh_digitalassets/documents/digitalasset/ dh_080803.pdf. Accessed November 17, 2011. 
16. Fisons ceases manufacture of Imferon. The Pharma Letter. 1993. Available at: http://www.thepharmaletter.com.file/92668/fisons-ceasesmanufacture-of-imferon.html. Accessed October 19, 2011.

17. Critchley J, Dundar Y. Adverse events associated with intravenous iron infusion (low molecular weight iron dextran and iron sucrose): a systemic review. Transfus Altern Transfus Med. 2007;9(1):8-36.

18. Venofer (iron sucrose) [summary of product characteristics]. London: Vifor Pharma UK Ltd; 2011 [updated March 30]. Available at: http://www.medicines.org.uk/EMC/medicine/24168/SPC/ Venofer+(iron+sucrose)/. Accessed November 9, 2011.

19. CosmoFer [summary of product characteristics]. London: Pharmacosmos UK Ltd; 2011 [updated January 27]. Available at: http://www.medicines. org.uk/emc/medicine/14139/SPC/CosmoFer/. Accessed October 19, 2011.

20. Bhandari S. A hospital-based cost minimization study of the potential financial impact on the UK health care system of introduction of iron isomaltoside 1000. Ther Clin Risk Manag. 2011;7:103-113.

21. Rawn J. The silent risks of blood transfusion. Curr Opin Anaesthesiol. 2008;21(5):664-668.

22. Bhandari S, Brownjohn A, Turney J. Effective utilization of erythropoietin with intravenous iron therapy. J Clin Pharm Ther. 1998;23(1):73-78.

23. Weiss G. Pathogenesis and treatment of anemia of chronic disease. Blood Rev. 2002;16:87-96.

24. Auerbach M, Coyne D, Ballard H. Intravenous iron: from anathema to standard of care. Am J Hematol. 2008;83:580-588.

25. Fishbane S, Frei GL, Maesaka J. Reduction in recombinant human erythropoietin doses by the use of chronic intravenous iron supplementation. Am J Kidney Dis. 1995;26(1):41-46.

26. Melamed N, Ben-Haroush A, Kaplan B, Yogev Y. Iron supplementation in pregnancy - does the preparation matter? Arch Gynecol Obstet. 2007;276(6):601-604

27. McClelland DBL, editor. Handbook of Transfusion Medicine. 4th ed. London: Stationary Office. 2007. Available from: http://www. transfusionguidelines.org.uk/docs/pdfs/htm_edition-4_all-pages.pdf. Accessed February 9, 2011.

28. Van Wyck D, Anderson J, Johnson K. Labile iron in parenteral iron formulations: a quantitative and comparative study. Nephrol Dial Transplant. 2004;19:561-565

29. Geisser P, Baer M, Schaub E. Structure/histotoxicity relationship of parenteral iron formulations. Arzneimittelforschung. 1992;42(12): 1439-1452.

30. Zager RA, Johnson AC, Hanson SY. Parenteral iron nephrotoxicity: potential mechanisms and consequences. Kidney Int. 2004;66:144-156.
31. Zager RA, Johnson AC, Hanson SY, Wasse H. Parenteral iron formulations: a comparative toxicologic analysis and mechanisms of cell injury. Am J Kidney Dis. 2002;40(1):90-103.

32. Agarwal R, Vasavada N, Sachs NG, Chase S. Oxidative stress and renal injury with intravenous iron in patients with chronic kidney disease. Kidney Int. 2004;65:2279-2289.

33. Doncaster and Bassetlaw Hospitals NHS Foundation Trust. Staff crack down on wasted ambulance journeys. Doncaster: Doncaster and Bassetlaw Hospitals NHS Foundation Trust. Available at: http://www. dbh.nhs.uk/Staff crack_down_on_wasted_ambulance_journeys.asp. Accessed March 2, 2010.

34. Bhandari S, Naudeer S. Improving efficiency and value in health care. Intravenous iron management for anaemia associated with chronic kidney disease: linking treatment to an outpatient clinic, optimizing service provision and patient choice. J Eval Clin Pract. 2008;14: 996-1001.

35. Curtis L, compiler. Nurses [sections 12.1 and 12.2]. Unit Costs of Health and Social Care, 2009. Canterbury: Personal Social Services Research Unit University of Kent; 2009. Available at: http://www.pssru.ac.uk/pdf/ uc/uc2009/uc2009_s12.pdf. Accessed September 15, 2010.

36. Curtis L, compiler. Nurses [sections 14.1 and 14.2]. Unit Costs of Health and Social Care, 2010. Nurses (sections 14.1 and 14.2). Canterbury: Personal Social Services Research Unit University of Kent; 2009. Available at: http://www.pssru.ac.uk/pdf/uc/uc2010/uc2010_s14.pdf. Accessed June 27, 2011.

37. Venofer (Vifor). British National Formulary. London: The Stationary Office; 2011. Available at: http://bnf.org/bnf/bnf/current/129558. htm\#_129558. Accessed October 19, 2011.

38. Cosmofer (Pharmacosmos UK). British National Formulary. London: The Stationary Office; 2011. Available at: http://bnf.org/bnf/bnf/ current/75068.htm\#_75068. Accessed October 19, 2011.

39. Ferinject (Vifor). British National Formulary. London: The Stationary Office; 2011. Available at: http://bnf.org/bnf/bnf/current/201168. htm\#_201168. Accessed October 19, 2011.

40. Monofer (Pharmacosmos UK). British National Formulary. London: The Stationary Office; 2011. Available at: http://bnf.org/bnf/bnf/current/213591.htm\#_213591. Accessed October 19, 2011.

41. Organ Donation. NHSBT Annual Review 2009/10: Saving and Improving Lives [news release]. Bristol: NHS Blood and Transplant; 2010. Available from: http://www.organdonation.nhs.uk/ukt/newsroom/ news_releases/article.jsp?releaseId=249. Accessed June 27, 2011.
Therapeutics and Clinical Risk Management

\section{Publish your work in this journal}

Therapeutics and Clinical Risk Management is an international, peerreviewed journal of clinical therapeutics and risk management, focusing on concise rapid reporting of clinical studies in all therapeutic areas, outcomes, safety, and programs for the effective, safe, and sustained use of medicines. This journal is indexed on PubMed Central, CAS,

\section{Dovepress}

EMBase, Scopus and the Elsevier Bibliographic databases. The manuscript management system is completely online and includes a very quick and fair peer-review system, which is all easy to use. Visit http://www.dovepress.com/testimonials.php to read real quotes from published authors. 